\title{
Development of a Comparison Based Hotel and Resort Booking System in Bangladesh
}

\author{
Md. Sajjad Mahmud Khan, Sajjad Kashem, Mohammad Monirujjaman Khan \\ Department of Electrical and Computer Engineering, North South University, Dhaka, Bashundhara \\ Email: sajjad0mahmud@gmail.com, sajjadkashem24@gmail.com, monirujjaman.khan@northsouth.edu
}

How to cite this paper: Khan, Md.S.M., Kashem, S. and Khan, M.M. (2021) Development of a Comparison Based Hotel and Resort Booking System in Bangladesh. Journal of Software Engineering and Applications, 14, 133-149.

https://doi.org/10.4236/jsea.2021.145009

Received: March 1, 2021

Accepted: May 11, 2021

Published: May 14, 2021

Copyright $\odot 2021$ by author(s) and Scientific Research Publishing Inc. This work is licensed under the Creative Commons Attribution International License (CC BY 4.0).

http://creativecommons.org/licenses/by/4.0/

(c) (i) Open Access

\begin{abstract}
With the rise of population and the industrial revolution, it is obvious that hotels and resorts are increasing drastically day by day. In the 21 st century, tourism is a trend. Everyone loves to travel and the reasons vary from person to person. Whether it is to have a cheerful and peaceful mind and place or business purposes, either way, hotels and resorts actually doing their jobs very well. This, tourism is a promising sector for any country and Bangladesh is no different. But the problem is we have to do the hotel booking and reservation manually most of the time. Sometimes it is too troublesome and knowing about the suitable hotels and resorts is too difficult. Though there are some online platforms available, they are not our country-oriented such as the payment system is not preferable for us. To solve this problem Vhromon is developed, a comparison-based hotel and resort booking system where anyone can book a hotel or resort by just login from the internet. Vhromon is an interactive online platform and it is user-friendly and easy to get like most of the platforms available nowadays. But they do not have all the hotels and resorts enlisted, only the well-known ones. On the other hand, Vhromon has everything enlisted where customers can compare them and can choose the right one for them. Furthermore, this system has a vendor panel where any hotel or resort owner can add their hotel or resort easily without any hassle, unlike the existing one.
\end{abstract}

\section{Keywords}

Hotel Booking, Hotel Comparison, Resort Booking, Resort Comparison, Hotel Search, Hotel Reviews, Resort Search, Resort Reviews, Hotel Ratings, Resort Ratings

\section{Introduction}

The process of booking or reservation a resort or a hotel is a frequent activity 
and plays an important role in a place where people love to travel and spend their leisure time with family. But the process is tiresome and time-consuming since there is no proper and convenient system. We have to book a resort or a hotel manually by a person or by a phone call. This is not the only problem; we also don't have many options to choose between the resorts since we don't know how many resorts or hotels are there. To deal with this problem an online resort booking platform is necessary. Online resort booking system simply can be accessed by a computer or laptop with an internet connection. This online resort booking system will have information about the resorts and hotels. People can book online anytime and anywhere with a proper internet connection. People can book the available rooms of resorts and hotels online and also will be able to pay online. This website will have all the necessary information about the resorts and hotels in a specific place and can be accessed by anyone at anytime.

There are many tourist spots in Bangladesh that foreigners or local people have visited or want to visit in the future. Among them, Cox's Bazar, Sundarbans, Sonargaon, Chittagong Hill Track, Old Dhaka is much more famous than others tourist spots like Rangamati, Khagrachori, Kuakata, Sylhet, Bandar ban, Shajek, etc. (Figure 1).

In terms of the TOM (Top of Mind), Cox's bazaar is observed in the first position by $46.9 \%$ of the foreigners that are followed by Sundarbans (21.9\%), Sonargaon (6.3\%), old Dhaka (6.3\%) Chittagong Hill Tracks (6.3\%), Rangamati (3.1\%), Kuakata (3.1\%), Sylhet (3.1\%), and Bandar ban (3.1\%) [1]. Though these are some famous tourist spots in Bangladesh, there are only a few standard hotels and resorts available in Cox's Bazar and Old Dhaka that people know about. Many people don't even know the information about hotels or resorts in Sundarbans, Rangamati, Kolkata, etc. And that's the gap that we are trying to close with our website by giving relevant information about hotels and resorts in different tourist spots.

\section{Literature Review}

In the 21st century when everyone owns a mobile phone and can access almost anything with it, it is a great opportunity for the tourists and travel enthusiastic to explore the world. Bangladesh has 10 major tourist spots but it is a matter of sorrow that only 2 or 3 of them are well known to the world. The other spots also have magnificent view and nature but as they lack the popularity, people don't feel comfortable to go there. The number of foreign tourists' arrival in Bangladesh increased over the past five years. The number of foreign tourists was about 0.16 million in 2014 which slightly declined in 2015 reaching 0.14 million, before increasing again to 0.20 million in 2016, about 0.26 million in 2017, around 0.27 million in 2018 and about 0.20 million up to July 2019 [2]. Bangladesh's tourism sector has grown with the pace of the country's economic growth in the past decade, as more and more people are having sizeable disposable income. In the past decade, the economy grew at an average of 6.5 percent; and in the last 


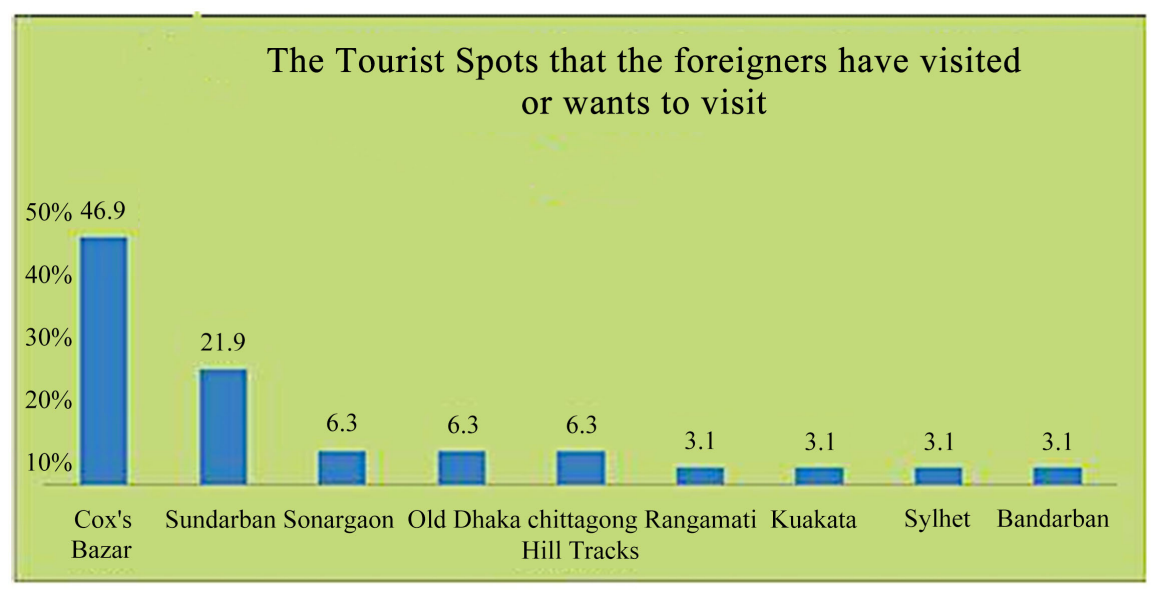

Figure 1. Popular tourist spot in bangladesh [1].

three years it clocked in more than 7 percent growth. At the end of last fiscal year, the per capita income stood at $\$ 1751$, in contrast to $\$ 703$ nine years earlier [3].

International tourism receipts are expenditures by international inbound visitors, including payments to national carriers for international transport. These receipts include any other prepayment made for goods or services received in the destination country. They also may include receipts from same-day visitors, except when these are important enough to justify separate classification. For some countries they do not include receipts for passenger transport items. Data are in current U.S. dollars (Figure 2).

- Bangladesh tourism statistics for 2018 was $357,000,000.00$, a $2.59 \%$ increase from 2017.

- Bangladesh tourism statistics for 2017 was $348,000,000.00$, a $62.39 \%$ increase from 2016.

- Bangladesh tourism statistics for 2016 was $214,300,000.00$, a $42.58 \%$ increase from 2015.

- Bangladesh tourism statistics for 2015 was $150,300,000.00$, a $2.4 \%$ decline from 2014 [4].

These data clearly show that tourism in Bangladesh is increasing day by day. Because of that demand our system will sustain longer in Bangladesh. Even after this growth in tourism, there is no proper website available to show the available services or resorts that are present in Bangladesh. There are only few websites available that shows the hotels and resorts available for booking but only for Cox's Bazar and Sylhet.

Booking.com [5] is one of the sites that show only the well-known and available hotels/resorts for Bangladesh. User can search these locations and find the available hotels and resorts. User also can see the quality and the price in this website. But user cannot compare the prices with other websites. There is also not enough information about the location itself. Other websites which are similar to this one such as Hotels.com [6] Trivago.com [7], Agoda [8], and Kayak.com [9], 


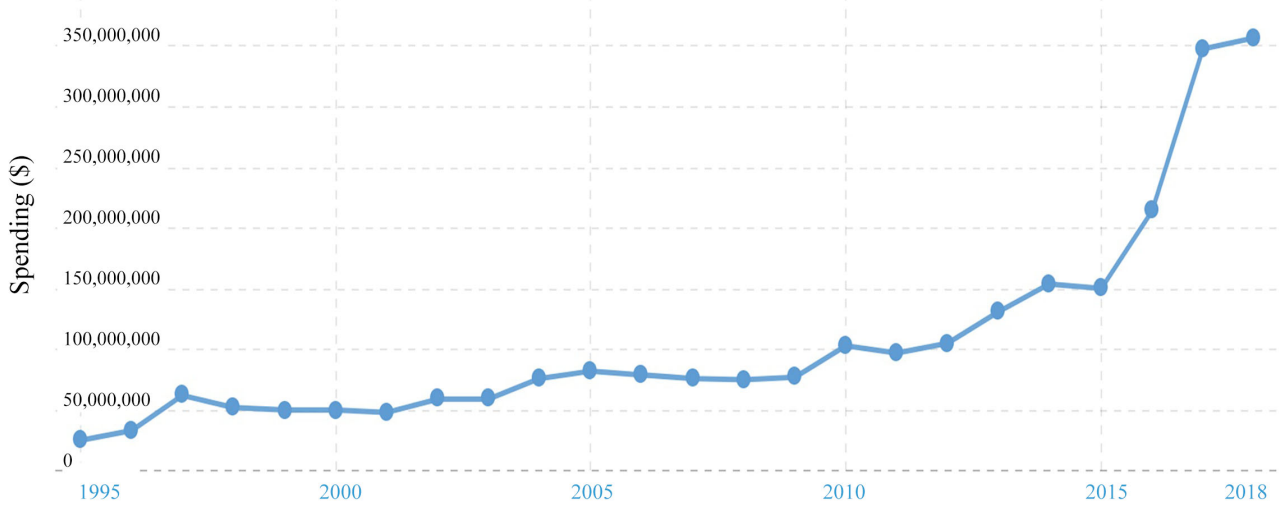

Figure 2. Bangladesh tourism statistics [4].

Trip.com [10], Expedia [11]. But trivago is bit different from the rest of them. In trivago user can compare prices with the other websites such as Booking.com, Kayak.com, Trip.com, Expedia etc. But all of them failed to cover a vast majority of resorts and hotels. Furthermore a place likes Bangladesh where every year millions of tourist visit, it is a matter of sorrow that there is no proper website to guide them along their journey. All of the websites don't have sufficient information and don't cover every resort that is available. Because of the lack of proper website in Bangladesh, People suffer to get a proper resort.

Problems: Dhaka is the most populated city in Bangladesh, and it is also one of the most populated cities in the world. The Greater Dhaka Area has a population of over 18 million as of 2016, while the city itself has a population estimated at 8.5 million (Ashiq, 2018) [12]. It creates tension in the city and hence affects both the people and the resort organizations. Dhaka is the main and busy city of Bangladesh and inside or outside of this city there are so many hotels and resorts to fulfill the needs of the people who love to travel and want to spend their leisure time in a peaceful place with family to relax and enjoy their moment. Some of the hotel and resort owner wish to show the country what they have to offer to help in situation like this. But they don't know how. There are so many resorts and hotels inside or outside of Dhaka which are not known by many people and those who are aware of these resorts don't know how good they are. Furthermore, people do not know much information of a resort and always have to book a resort by person. Even if one books a resort over phone, they know what the owner tells them. And it's a big issue that even if someone gets a resort but not satisfied about the quality and the services. So we can sum up the problems as,

- Customers don't know much about the resort and hotel (less specification).

- Time consuming since sometimes customers have to book a resort by person or over phone.

- Customers don't have many options to choose since they are not aware of some of the resorts.

- Don't have the options to look before visiting. 
- Customers don't have the option to compare between two similar resorts.

So all the points described in the problem statement needs to be resolved by the use of information and technology and for this matter this project is being undertaken to look at how problems can be solved or reduced and to provide a web based application that can allow the user to search, look, compare and reserve a resort or cancel the reservation anytime anywhere.

Solutions: "Vhromon-A Online Resort and Hotel Booking System" is developed to solve the given problems. In this web platform customers can search and look all the available resorts and hotels. Customers can compare between the similar resorts or hotels of a specific location. They also can book resorts online and the payment can be done online also.

Although there are few similar system is already live but there are some major differences between this system and the existing ones. Table 1 below illustrates the key differences between vhromon and the existing ones.

In this "Vhromon-A Online Resort and Hotel Booking System" people can search for different resorts and compare them online. They can book or reserve a resort online. In this system there are two panels; one is for admin and the other one for users. Customers have to sign up first to access the website. Guest user or just the normal user who doesn't sign up can also search and look for resorts. But to book or make payment customers have to sign in. Whoever has an account will have a user profile where all the user information will be stored and they also can edit their information. User can rate a resort or hotel according to their likeness. Customers also can cancel their reservation within the given time. User information is secured in our platform and no third party can access it from us. Admin panel is for the admin/company. Admin can add new information to the database and also can delete from the database. Admin is also able to delete user from the database if fraudulence detected.

This web application can be accessed by everyone who owns a computer or laptop and has the internet access. However, to make booking a resort or payment, one must sign in to access these facilities. The people who are travel enthusiastic and want to spend a quality time in a peaceful place, for them this will be a good thing to have this platform where they can easily search and find the place they really like.

\section{Methodology}

In order to achieve the desired system, some traditional methods were used such as block diagram of the system, entity relationship diagram of the database and finally developed the system using the necessary languages and tools. Then testing and validation were conduct to check for errors in the system.

System Requirements: The system needs to have a front-end which not only makes the web user-friendly but also makes modifications easier. Likewise, the back-end must be sufficiently reliable to support the front end comfortably and also versatile enough to respond to any structural reforms within the front end. For this system, the following tools were used: 
Table 1. Key differences between the vhromon and the similar websites.

\begin{tabular}{|c|c|c|}
\hline Differences & Vhromon.com & Similar website \\
\hline Coverage & Vhromon.com is covering almost every tourist spot in Bangladesh. & They only cover the well-known tourist spot. \\
\hline User Interface & $\begin{array}{l}\text { UI in vhromon.com is much more user friendly than any other } \\
\text { available system }\end{array}$ & Not user friendly and sometimes confusing. \\
\hline Security & $\begin{array}{l}\text { The confidentiality of clients data is highly maintained and will } \\
\text { not be disclosed for unauthorized personal }\end{array}$ & $\begin{array}{l}\text { Many agencies can easily get those data from other } \\
\text { system and use it for their own benefit. }\end{array}$ \\
\hline Payment gateway & $\begin{array}{l}\text { The payment gateways in vhromon.com are the most popular one } \\
\text { in Bangladesh }\end{array}$ & $\begin{array}{l}\text { Users find it very difficult to pay advance while } \\
\text { booking a room online }\end{array}$ \\
\hline Vendor Friendly & Vendor can enlist their hotel or resort easily from vendor panel & They rarely offer such kind of facility \\
\hline
\end{tabular}

\section{1) Front End:}

HTML and CSS: According to Tim Berners-Lee (1998), HTML which stands for Hypertext Markup Language is the predominant markup language for web pages, a building block of web pages. A web browser reads HTML documents and composes them into visual or audio web pages. The browser does not display the HTML tags but uses the tags to interpret the content of the page [13] [14] [15].

Web browsers can also refer to Cascading Style Sheets (CSS) to define the appearance and layout of text and other materials (Taylor, 2013) [13] [16]. The W3C, maintainer of both HTML and the CSS standards, encourages the use of CSS over explicitly presentational HTML Markup (Debolt, 2007) [13] [17].

JAVASCRIPT: JavaScript is an implementation of the ECMA Script language standard and is primarily used in the form of client-side JavaScript, implemented as part of a web browser in order to enhance user interfaces and dynamic websites (McFarland, 2008) [18]. This enables programmatic access to computational objects within a host environment [13].

\section{2) Back End:}

PHP: PHP is a general-purpose scripting language originally designed for web development to produce dynamic web pages. For this purpose, PHP code is embedded into the HTML source document and interpreted by a web server with a PHP processor module, which generates the web page document (Pan, Chen, and Nguyen, 2012) [19].

SQL: SQL is a computer language designed for the management and retrieval of data in a database management system often referred to as Structured Query Language, designed for managing data in RDMS and originally based on relational algebra and calculus (Ghosh, 2010) [20].

\section{3) Framework:}

Laravel is an open-source PHP framework, which is robust and easy to understand. It follows a model-view-controller design pattern. Laravel reuses the existing components of different frameworks which help in creating a web application. The web application thus designed is more structured and pragmatic.

Laravel offers a rich set of functionalities which incorporates the basic features 
of PHP frameworks like CodeIgniter, Yii and other programming languages like Ruby on Rails. Laravel has a very rich set of features which will boost the speed of web development. If someone is familiar with Core PHP and Advanced PHP, Laravel will make their task easier. It saves a lot time if someone is planning to develop a website from scratch. Moreover, a website built in Laravel is secure and prevents several web attacks.

4) Software:

XAMPP Control Panel/MAMP

VS Code

Sublime Text

5) Operating System:

Windows

Linux

Mac OS

Block Diagram: The block diagram represents the system work flow that shows how the system will work. In this system there are two block diagram, one is for user and the other one is for admin. The system is simple and straight so that everyone can understand how the system works by just looking at it.

Figure 3 below represents the functions of user where a user will have a profile and can search, look, book and make payment. Basically, User will go to online. He can check his profile, sign up, login and booking his/her resorts.

Figure 4 below represents the functions of admin. The functions and features of admin are similar to a user but admin also has the authority to add and remove features to the system. In addition to that admin can add and remove hotels and resorts to the system.

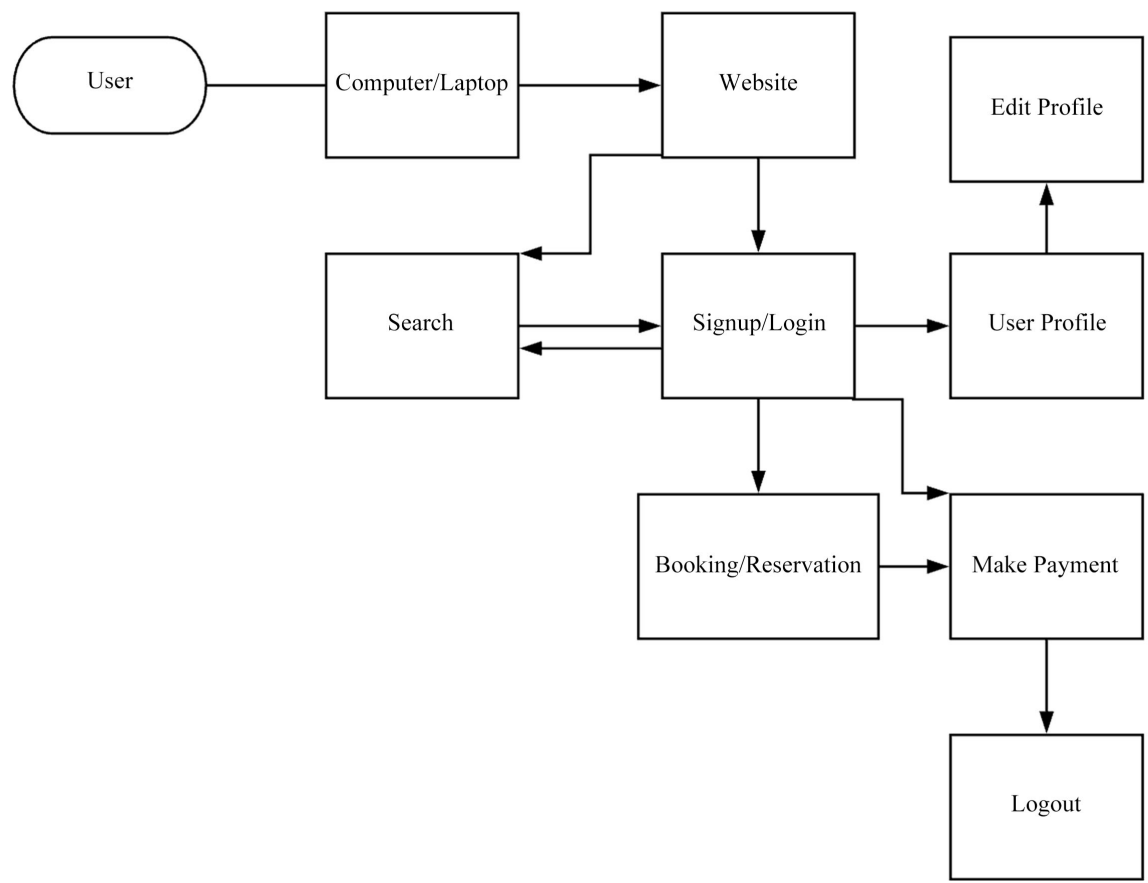

Figure 3. Block diagram for the user of the system. 


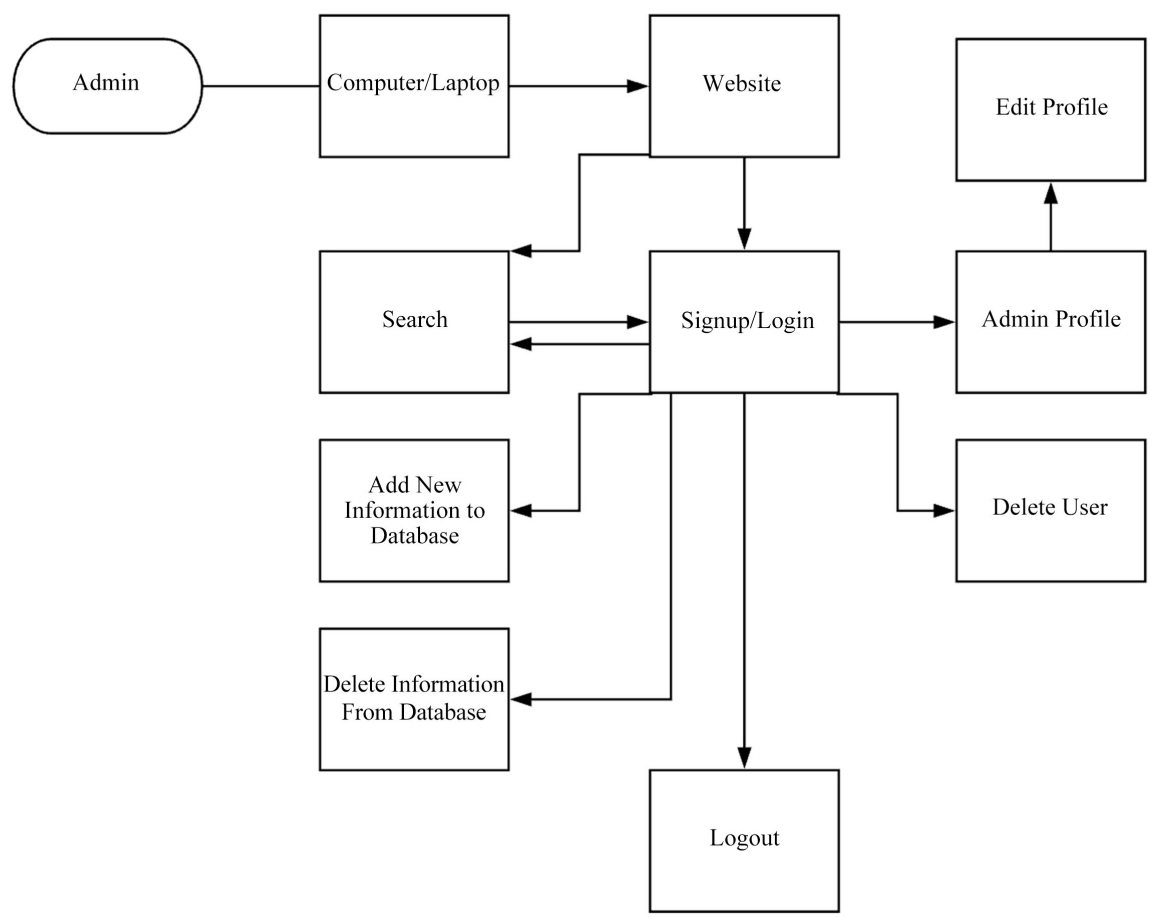

Figure 4. Block diagram for the admin of the system.

Entity Relationship Diagrams: ERD illustrates the logical structure of databases. It was helpful to establish the entities and their relationships in the system. They were used because they are relatively simple, user friendly and can provide a unified view of data, which is independent of any data model.

System Design: In this section the system design will be explored through pictorial illustrations which will help to visualize the system before getting hold on to it physically. This section entails the step by step process on how the system works. With the help of the figure reader will be able to understand everything about the system.

\section{Home Page}

Figure 5 shows an interactive home page for the system. In this Home Page user can search for the desire hotel and resort. Any user can have this facility without signing in. In order to place a booking a user must sign in. Beside the search engine, on the right corner the system has login/signup option. Furthermore contact information, hotel listing and other pages are available in the Home Page.

\section{Search Engine}

Figure 6 shows the search engine of the system Vhromon.com. It also shows the result of hotels in Uttara. User can search any hotel by the location. Furthermore user can filter the search. In Figure 6, the result shows a hotel named Platinum and its facilities, location, rating, price etc.

\section{Login/Signup}

Figure 7 shows our system's login page. When a user clicks on login button it will pop up on the screen rather than opening a new page. To login, a user only 
needs an email address and password. If the user forgets the password then the user can change it with the email address provided. Furthermore, one can go to the signup page from this page if he/she is not a member.

Figure 8 is the signup page. If a user is not a member already then he/she can sign up using only email address, first name and last name. If the user is already a member then the user can go to the login page from this page.

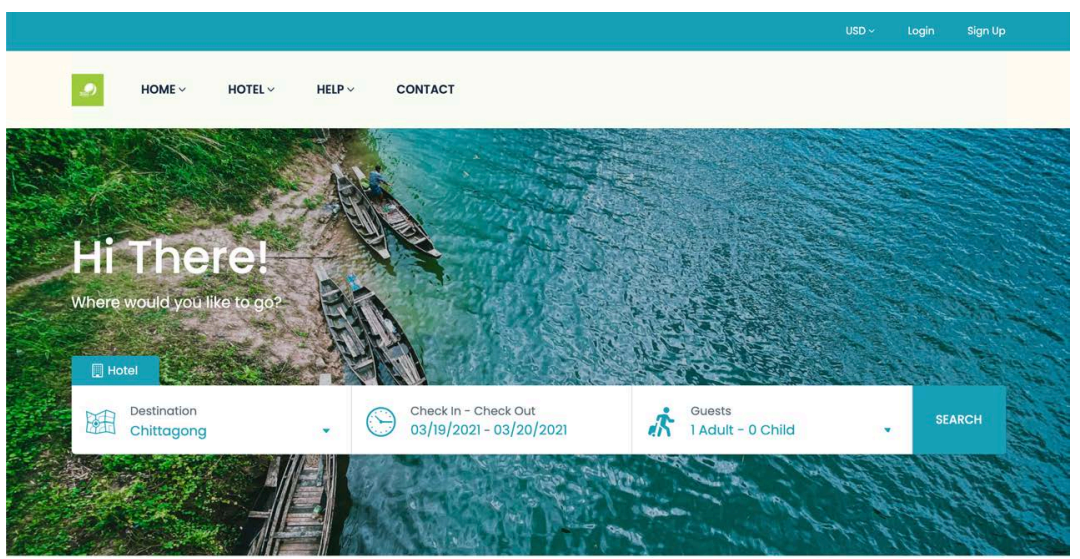

Figure 5. Home page of vhromon.

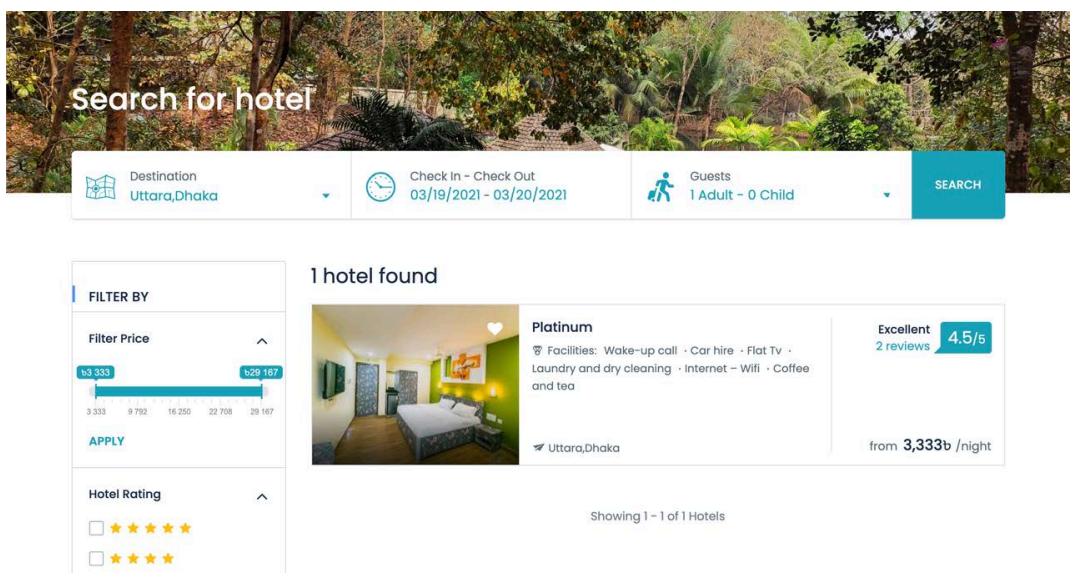

Figure 6. Search engine of vhromon.

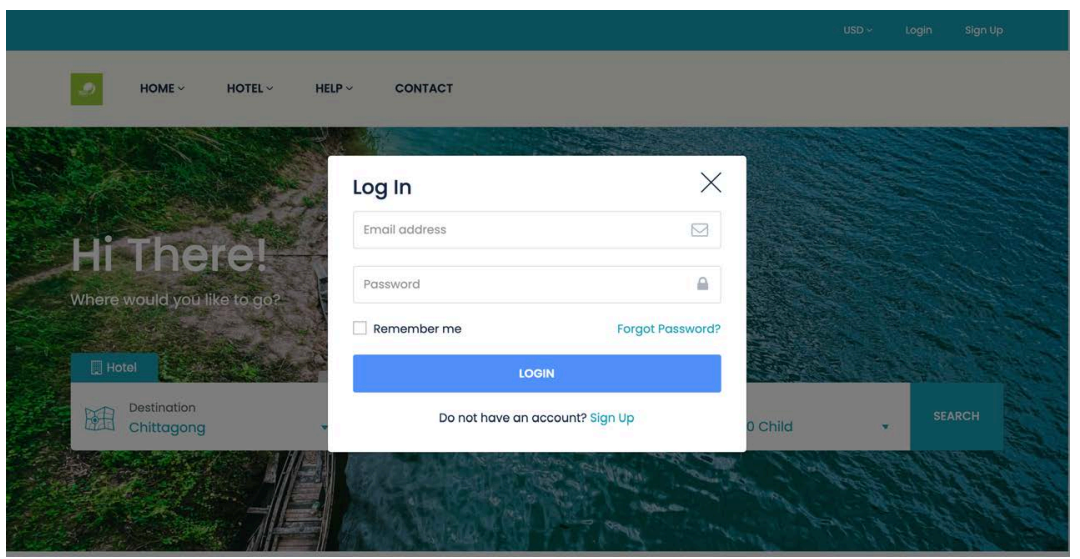

Figure 7. Login page. 


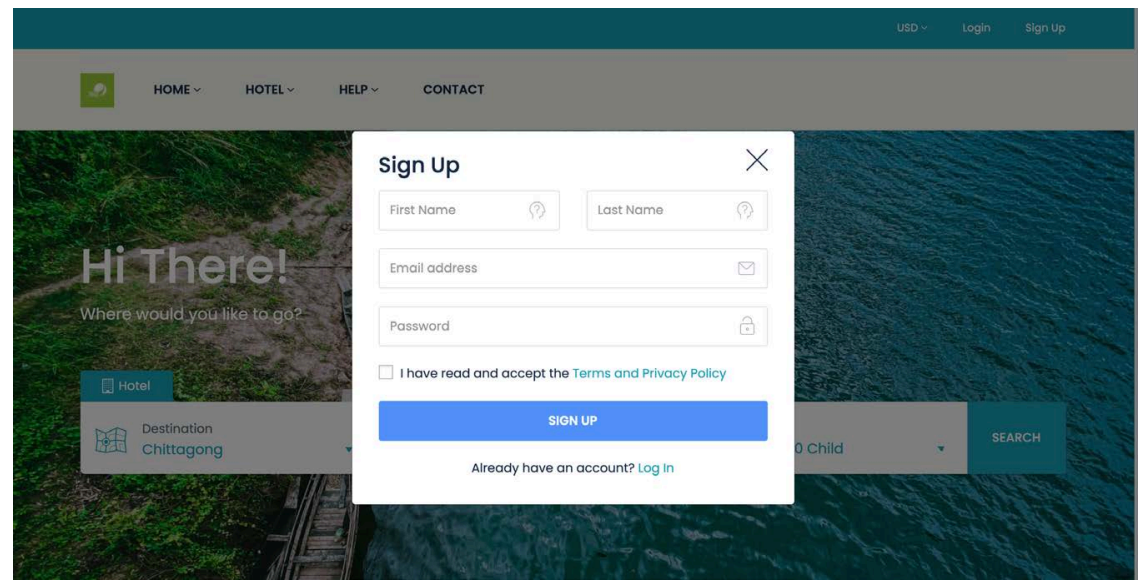

Figure 8. Signup page.

\section{Booking Page}

Figure 9 shows the booking page of the system. After selecting a specific hotel or resort, this booking page appears. In this booking page customer can check the availability of the rooms and upon selecting from various options, the customer finally can book a hotel room. In the above figure two options were introduced, double deluxe and suite room. User also can see the information about these options and can select from these options. This figure shows that one double deluxe room selected and with the service charge the total price shown. Upon clicking book now button it will take the customer to the confirmation page where customer will give the necessary information and payment method to confirm the booking. The rules show the check in and check out time. This page also provides the necessary information about the hotel such as the facilities, hotel services and property type etc.

\section{Confirmation/Payment Page}

Figure 10 illustrates the payment page. Here customer will give their necessary information to confirm the booking. The right side of the page shows the current booking and total payment. Customer has to select a payment method to place the booking. In this case offline patent is available and upon selecting the payment method the booking is done. After filling up all the requirements a confirmation message will be shown and a mail will be sent to the customer email address. Figure 11 below illustrates the confirmation page where a confirmation message will be sent upon completing the booking process.

\section{Profile Page}

Figure 12 below illustrates the profile page of the system. The profile page is similar for customer, admin and vendor. In this page one can edit personal information and location information. Customer also can change the password here. In the personal information section user can change his/her email address, date of birth, first name, last name etc. On the other hand, in location information section user can change address, delete and edit addresses as well. From this page user can go to the other pages also. 


\section{Admin Panel}

Figure 13 illustrates the admin panel of the system. In this panel the dashboard is shown. The dashboard is similar for all the user, admin and vendor. In admin panel all the features and access available for admin. The dashboard shows the total earning, revenue and booking.

\section{Manage Hotels}

Figure 14 illustrates that admin can edit hotels. Furthermore admin can add or delete hotels.

\section{Admin Dashboard}

Figure 15 illustrates the admin dashboard which is different from the dashboard. In here admin has all the access. From here admin can remove user. Admin can also add hotel from here. Some important features handled from here. The necessary changes and update will be made from here.

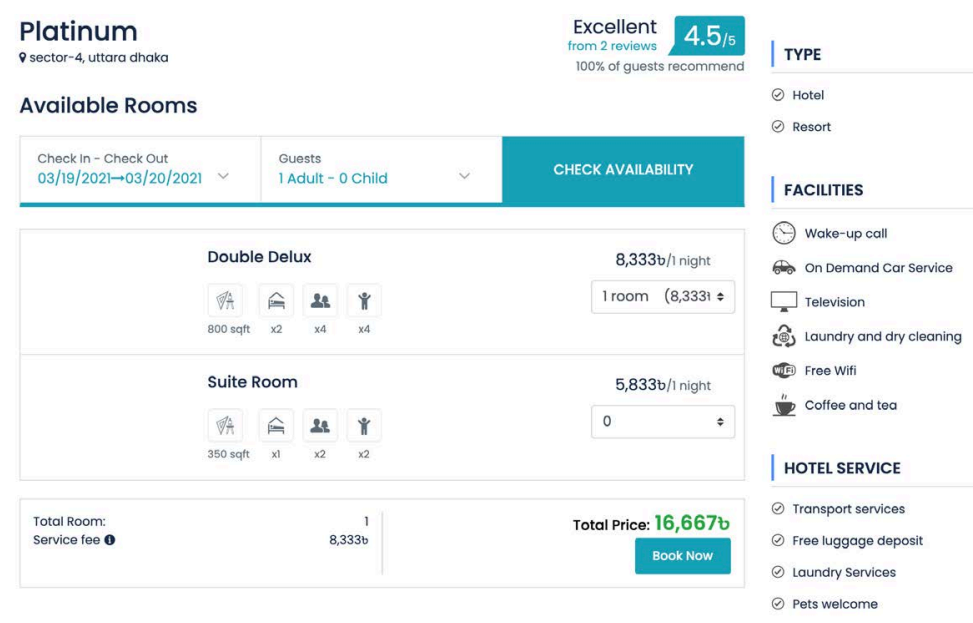

Figure 9. Booking page.

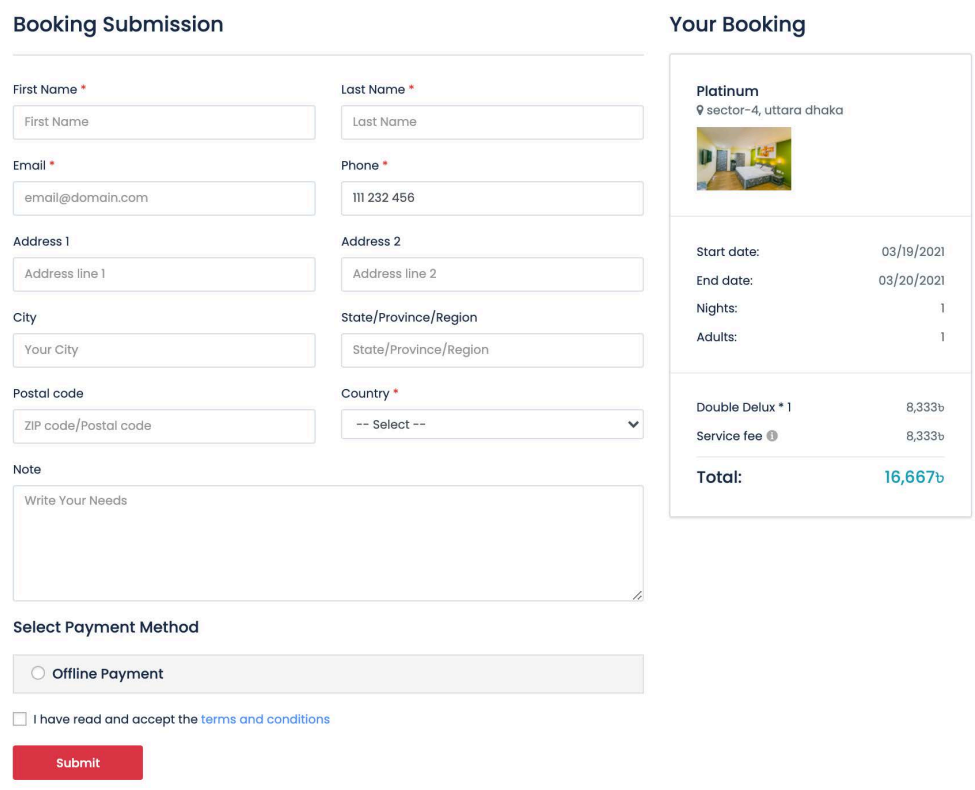

Figure 10. Payment page. 
John, your order was submitted successfully! Booking details has been sent to: johnd@email.com

Your Information

\begin{tabular}{lr}
\hline First name & John \\
\hline Last name & Doe \\
\hline Email & Johnd@email.com \\
\hline Phone & 111232456 \\
\hline Address line 1 & \\
\hline Address line 2 & \\
\hline City & \\
\hline State/Province/Region & \\
\hline ZlP code/Postal code & Antarctica \\
\hline Country & \\
\hline Special Requirements &
\end{tabular}

Booking Number: 8

Booking Date: $03 / 19 / 2021$

Payment Method: Offline Payment

Your Booking

Q sector-4, uttara dhaka

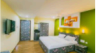

start date:

End date:

Nights:

Adults:

Double Delux*1

Service fee 0

Total:

$03 / 19 / 2021$ $03 / 20 / 202$

\section{Booking History}

Figure 11. Confirmation page.
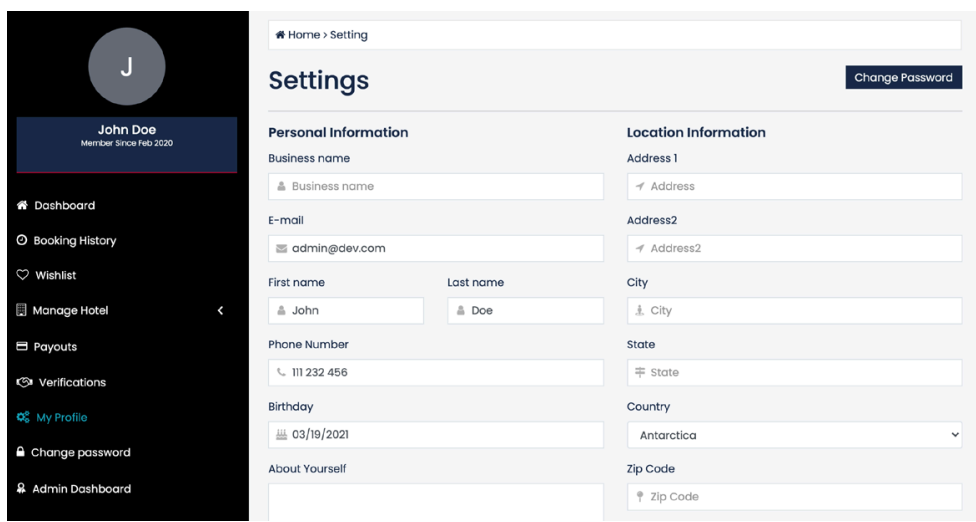

Figure 12. Profile page.
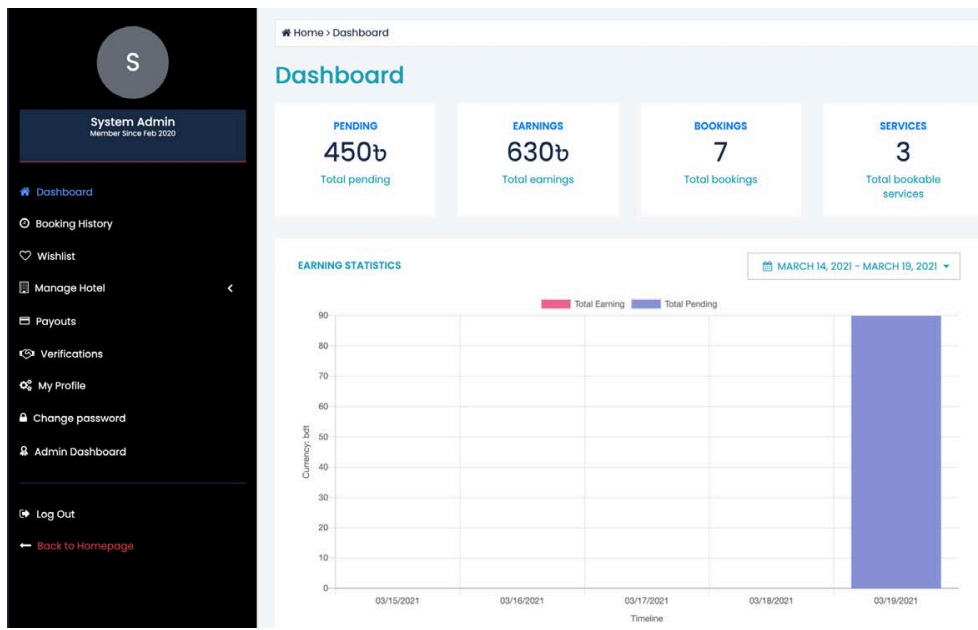

Figure 13. Admin panel. 

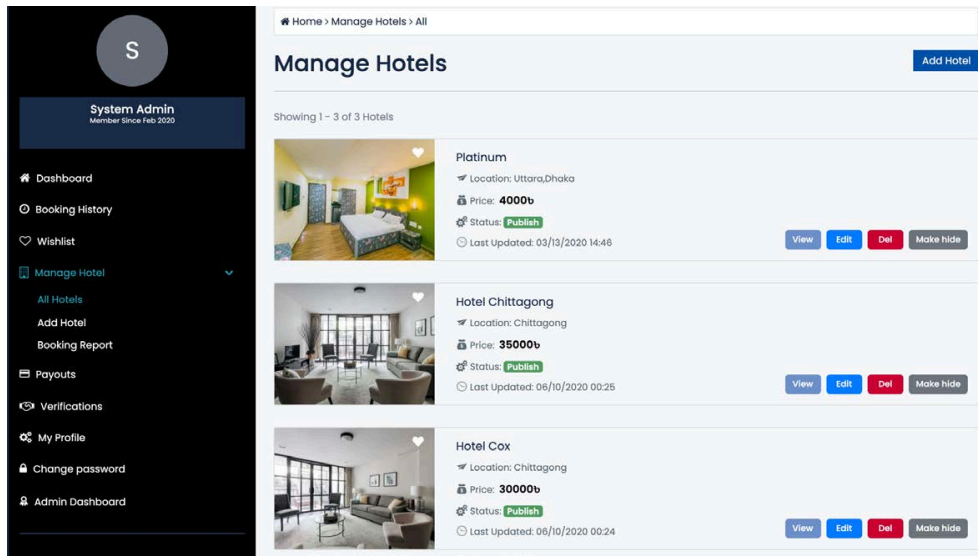

Figure 14. Manage hotels page.

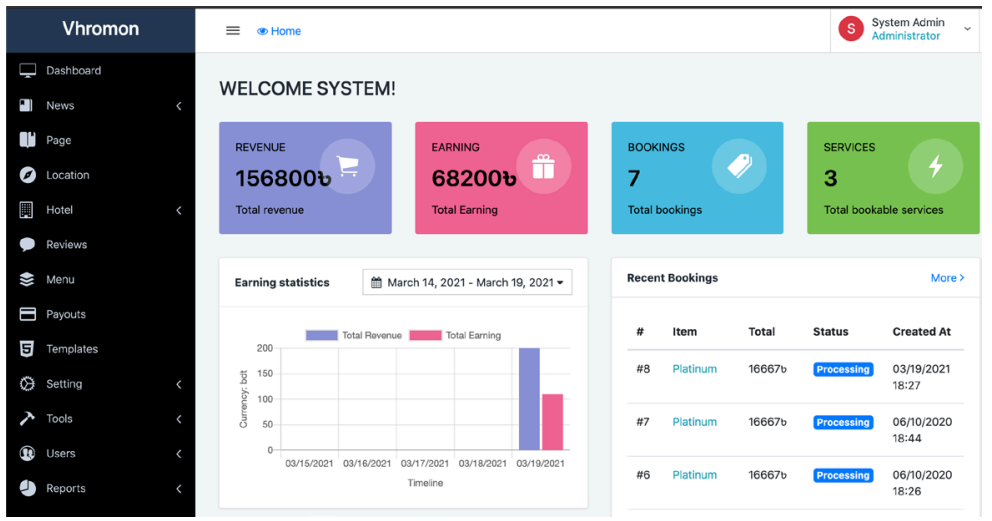

Figure 15. Admin dashboard.

\section{User Panel}

Figure 16 illustrates the user panel where user can edit his/her personal information and location information. Furthermore from this page user can change password. Customer can see booking history from here also. Customer can add the hotels and resorts to his/her wish-list.

\section{Vendor Panel}

Figure 17 shows the vendor panel. This panel is almost similar to the user panel except vendor can add or remove hotels/resorts.

\section{Test and Validatation}

The system tested by running the programs and see if they have errors. After doing this we could able to run the programs without any errors.

The system presented to the user to interact with it under observation and also presenting the system to the experts. After analyzing the system, some minor errors were found and all the errors were properly dealt with.

\section{Design Impact}

In this chapter, various impacts will be discussed that the system has been able to generate. 


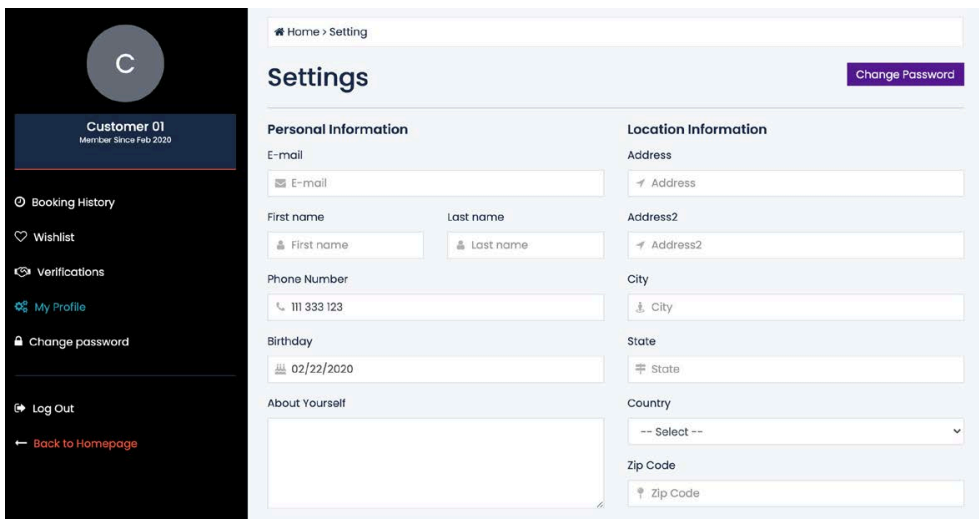

Figure 16. User panel.

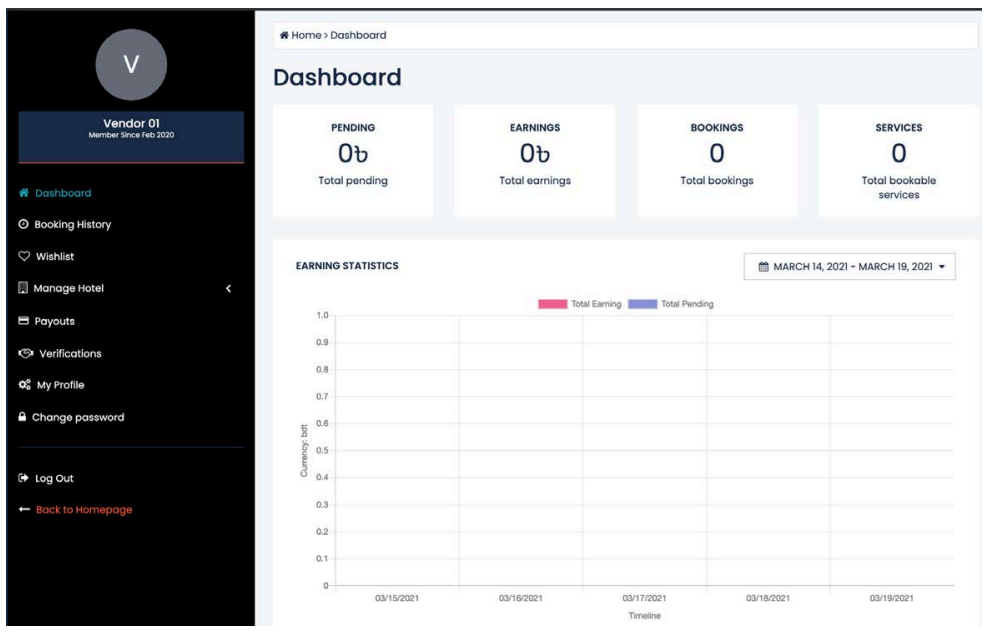

Figure 17. Vendor panel.

Environmental Impact: By introducing this system in an online based digitalized booking can reduce the use of paper as everything is done online or in the computers. The less use of paper has a huge impact on the environment as paper production process needs wood. The less paper needed, the less number of trees are cut down. Thus the environment can be well-kept.

Economic Impact: The economic impact that this system entails is that by introducing this system in an organisation, employees' salary can be reduced significantly as there would now require less man power to complete a certain task because the system is now automated and requires less human effort. As we can see the economy of Bangladesh, we have to think what exactly people want. We have done a simple research on it. First of all we do need to make sure about that what we sell in market that must go on which means demanded by the society. So one of thing is we have to keep the price low and quality high for increasing demand for consumers. So we are trying to make a system which going to add a nice look the history of tourism in Bangladesh.

- The tourism economy represents 5 percent of world GDP.

- Tourism contributes to 6 - 7 percent of total employment.

Social Impact: The Vhromon.com system will be socially acceptable as this 
kind of system is the need of the hour. In this era of ours, everything has been automated to provide comfort for the users. Therefore our system is no exception. Therefore, the social impacts of tourism are vital to ensuring the sustainable management of the tourism industry. There are positive social impacts of our system, demonstrating benefits to both the local community business and the tourists.

Sustainability: Our system has been able to deal with huge number of tourists' information at a time. Therefore based upon these facts and continuous testing, our system is sustainable. Initially, the project will run by the research grant. After the initial research and development phase, the service will be provided for free of cost for a limited amount of time. After a certain time span, a reasonable amount of money could be charged to get the service. The revenue earned from the project then can be invested to maintain the system and cover other costs to keep the system running and up to date.

This section has covered the different types of impacts that our system offers and those has been described and discussed. From the above given impacts we can conclude that our designed system is good enough to use under any circumstances.

\section{Target Population}

This project targets mainly for those who loves to travel and spend his/her holiday in a peaceful place. The services will be expanded alongside Bangladesh if the project runs successfully.

\section{Results}

The results were satisfactory and good since there was no error. Furthermore the system was able to book hotels and resorts successfully and the confirmation message of the booking received without any problems. From the beginning to the end of developing this system the following results has been achieved. They are as follows:

- The system can be administered by a non-IT technician.

- The system is market ready for commercial use.

- The system has the capacity to compare among hotels and resorts.

- The User Interface (UI) is tantalizing therefore it would attract more users.

- The system provides online booking resorts and also online finder gateway.

- The admin and users can have a one-to-one interaction through this system.

- The system can deliver high accuracy of information.

- The system is User-friendly.

- This will be a Budget-friendly site.

\section{Conclusion}

Vhromon is developed to replace the manual process of booking for a hotel room or any other facility of the hotels and resorts. The existing systems do not serve 
the customer in a better way; rather it makes customer data vulnerable. Our system keeps proper records of customers for emergency and security purposes. Vhromon covers every tourist spot in our country unlike any other existing system available. The quality and features are at the highest standard. The comparison section gives the users a chance to get the best deal that is available. It also helps the users to save some money on the process. Moreover, it brings the customers and hotel owners, even more, closer and gets the best deal for both of them. Besides this, the system is well designed and user-friendly compared to the other existing systems and it has many features altogether. Thus, this online hotel booking system can be an efficient, one-of-a-kind system for developing countries like Bangladesh.

\section{Acknowledgements}

Our sincere gratitude to the Department of Electrical and Computer Engineering of North South University for giving us this platform and opportunity of having an industrial level of experience as a part of the academics.

\section{Conflicts of Interest}

The authors declare no conflicts of interest regarding the publication of this paper.

\section{References}

[1] Tourism Scope and Major Tourist Spots in Bangladesh. https://www.assignmentpoint.com/arts/modern-civilization/tourism-scope-and-ma jor-tourist-spots-in-bangladesh.html

[2] Imam, S.H. (2019) Tourist Arrivals Rise in Five Years. The Financial Express. https://thefinancialexpress.com.bd/economy/tourist-arrivals-rise-in-five-years-1569 $\underline{469201}$

[3] Rahman, S. and Chakma, J. (2018) Tourism Booming with Economy. The Daily Star.

https://www.thedailystar.net/business/news/tourism-booming-economy-1673479

[4] Bangladesh Tourism Statistics 1995-2020. https://www.macrotrends.net/countries/BGD/bangladesh/tourism-statistics

[5] Booking.com. http://www.booking.com

[6] Hotels.com. http://www.Hotels.com

[7] Trivago.com. http://www.trivago.com

[8] Agoda.com. http://www.agoda.com

[9] Kayak.com. http://www.kayak.com

[10] Trip.com. http://www.trip.com

[11] Expedia. http://www.expedia.com

[12] Ashiq (2018) Dhaka Population 2019. http://worldpopulationreview.com/world-cities/dhaka-population

[13] Bemile, R., Achampong, A. and Danquah, E. (2014) Online Hotel Reservation System. International Journal of Innovative Science, Engineering \& Technology, 1, 583-588. 
[14] Berners-Lee, T. (1998) Web Design Issues. http://www.w3.org/DesignIssues/RDFnot.html

[15] Introduction to HTML. W3schools.com, 2020. https://www.w3schools.com/html/html_intro.asp

[16] Taylor, M. (2013) A General Understanding of Microsoft Excel, Visual Studio and Webmatrix2. Mark Taylor and Paragon Publishing, Rothersthorpe.

[17] DeBolt, V. (2007) Mastering Integrating Html and CSS.

[18] McFarland, D.S. (2008) Dreamweaver CS4: The Missing Manual. O’Reilly Media Inc., Sebastopol.

[19] Pan, J., Chen, S. and Nguyen, N. (2012) Intelligent Information and Database Systems. 4th Asian Conference, ACIIDS, Proceedings Part 2, Kaohsiung, 2012, 73-82.

[20] Ghosh, P. (2010) SQL Popcorn. PHI Learning, New Delhi. 